\title{
Distributed Leadership Agency and Its Relationship to Individual Autonomy and Occupational Self-Efficacy: a Two Wave-Mediation Study in Denmark
}

\author{
Christine Unterrainer ${ }^{1,2}$ (D) Hans Jeppe Jeppesen ${ }^{1}$ • \\ Thomas Faurholt Jønsson ${ }^{1}$
}

Received: 1 August 2016 / Accepted: 2 May 2017 / Published online: 22 May 2017

(C) The Author(s) 2017. This article is an open access publication

\begin{abstract}
The purpose of the present study is the investigation of distributed leadership agency (DLA). DLA is an activity-based concept, which is defined as employees' active participation in leadership tasks. By combining a descriptive and a normative approach DLA has the potential of real employee empowerment. It can protect from arbitrary managerial power and lead to employees' personal development through sharing organizational resources, influencing leadership activities and joint decision making in companies. The study examines individually perceived autonomy as an antecedent and employees' occupational self-efficacy as an outcome of DLA over time. Furthermore, the study tests the mediating role of DLA on the autonomy - selfefficacy relationship. The two-wave study applied an online survey in a Danish municipality with a time lag of seven months. We used regression analyses for testing the cross-sectional as well as cross-lagged relationships and an autoregressive model for analyzing the half-longitudinal mediation. The results revealed a significant positive effect of DLA on employees' occupational self-efficacy cross-sectionally at Time $1(n=117)$ and Time $2(n=67)$, as well as cross-lagged $(n=67)$. The cross-sectional and cross-lagged findings also support a significant positive impact of autonomy on DLA. However, DLA only mediated the autonomy-self-efficacy relationship cross-sectionally, but not over time. Computed alternative causal models corroborate the proposed direction of our hypothesized relationships. These results provide first evidence that structural features such as autonomy are timely prior to action-related behavior (DLA), and that participating in leadership tasks enhances employees' occupational self-efficacy.
\end{abstract}

Keywords Distributed leadership agency · Individual autonomy - Occupational self-efficacy · Collective leadership · Two-wave mediation

Christine Unterrainer

christine.unterrainer@uibk.ac.at

1 Department of Psychology and Behavioral Sciences, Aarhus University, School of Business and Social Sciences, Bartholins Allé 9, Building 1350, 8000 Aarhus C, Denmark

2 Institute of Psychology, University of Innsbruck, Innrain 52, A-6020 Innsbruck, Austria 


\section{Introduction}

Recently, collective forms of leadership such as distributed or shared leadership have gained much attention in organizational behavior literature (Denis et al. 2012; D'Innocenzo et al. 2014; Pearce et al. 2014; Wang et al. 2014). HR practitioners and organizational behavior researchers observed that nowadays the solely individualistic, leader-centered approaches are not so appropriate anymore. The classical top-down leadership models in which the leader influences their employees through a "unitary command" are becoming less useful as organizations are increasingly subject to a barrage of complex and rapidly changing environmental demands. Evident by an increasing number of flat, decentralized company structures and selfmanaging teams in organizations, distributed forms of leadership (e.g. distributed leadership, shared leadership, co-leadership, leadership couples or self-managed teams) seem better able to cope with high complexity and ambiguity common to today's organizational environment (Bolden 2011; Yammarino et al. 2012).

The present study refers to distributed leadership agency (DLA), a concept that is theoretically based on the conception of distributed leadership applying an Activity Theory approach (acc. to Gronn 2002; Spillane et al. 2004) and Bandura's (1997) Cognitive Theory of Agency. DLA is the degree to which all employees individually experience being actively engaged in leadership activities within organizational change, managing tasks and strengthening social relations at work (Jønsson et al. 2016) applying Yukl et al. (2002) metacategories of leadership behavior. This definition encompasses that all organizational members - with and without formal leadership function - can execute leadership tasks and it focusses the perspective of the individual as an agency. Tian et al. (2016) argue that for an individual in the context of distributed leadership “... agency is a vital presupposition for the ability to have ownership, empowerment, self-efficacy and well-being in the organization, both as an individual and through collective bodies" (p. 157). The added value of the presented DLA-construct in leadership literature is its humanistic potential to empower employees in the sense of real empowerment. This empowerment is obtained not simply by delegating leadership tasks, rather it is a function of sharing organizational resources, influencing leadership activities, and by actively participating in decision-making within the company (Conger and Kanungo 1988). Sharing power initiated by employees' decisions to actively take over leadership tasks provides opportunities for democratic processes (e.g. dialogue, developing mutual understanding, and reciprocal respect). Furthermore, Woods and Gronn (2009); Woods and Woods (2013) point to the democratic potential of distributed leadership: it can protect against arbitrary use of managerial power, lead to personal development and promote democratic citizenship through the permeation of democratic practices and values in organizations ensuring employees' basic human rights, such as dignity (McCall 2001; Pirson et al. 2016).

To date, distributed leadership research has either applied a descriptive (e.g. Gronn 2002; Spillane 2006) or a normative perspective (e.g. Hulpia et al. 2012; Mascall et al. 2008). Descriptive approaches use activity theory to describe different leadership configurations, however, they do not evaluate which are the preferred forms of distributed leadership. While scholars of normative distributed leadership recognize the beneficiary potential of distributing leadership functions, they do not consider an agentic perspective, such as activity theory (Mayrowetz 2008). The present DLA concept bridges these approaches by combining descriptive activity-agency with a normative framework. 
In the present research, we investigate the impact of DLA on employees' occupational self-efficacy over time. Self-efficacy - the individual's belief in his/her own competence (Bandura 1997) - plays a crucial role in the empowerment process as empowerment itself is assumed to be a process of enhancing self-efficacy (Conger and Kanungo 1988). We see in DLA an empowering practice that may make opportunities available to employees to participate in decision-making, which may strengthen their sense of responsibility on the job and provide opportunities to test their efficacy. We argue that employees' active participation in leadership tasks will provide them with those personal mastery experiences that are integral for developing self-efficacy (Bandura 1997). Empirically, only one study (Jønsson et al. 2016) has investigated the relationship between actively participating in leadership tasks (DLA) and employees' occupational self-efficacy; this study was a cross-sectional design and carried out in hospitals.

Considering factors that promote DLA, particular types of organizational culture and decentralized, flat organizational structures seem to encourage distributed leadership (Leithwood et al. 2007; Murphy et al. 2009; Woods et al. 2004). There is evidence to suggest that control and autonomy play an important role in the development of distributed leadership (Conger and Kanungo 1988; Woods et al. 2004). Autonomy is an organizational, contextual condition that enables employees to attempt new ways of accomplishing their work. It allows employees to take initiative and to participate in leadership tasks. Referring to Archer's (1982) theory of analytical dualism, we propose that autonomy is a structural feature that encourages individual action, especially employees' active participation in leadership tasks. Although there is qualitative evidence (Fitzgerald et al. 2013; Leithwood et al. 2007; Murphy et al. 2009) indicating that employee autonomy as an essential factor to facilitate distributed leadership, to date, no quantitative studies have investigated the positive impact of autonomy on DLA. Addressing this issue, in the present research we use a two-wave design to examine the importance of employees' autonomy as an antecedent of DLA.

Finally, combining Archer's (1982); Bandura's (1997) theories, we seek to find support for a mediational effect of DLA on the autonomy-self-efficacy relationship. We expect that DLA will be a mechanism through which autonomy will lead to increased self-efficacy.

\section{Review of Literature}

\section{Distributed Leadership}

Reviewing the concept of distributed leadership, we refer to the works of Gronn (2000, 2002, 2008, 2009) and Spillane et al. (2004; Spillane 2006; Spillane and Diamond 2007), which are currently the most comprehensive accounts in this field (Bolden et al. 2008). Gronn (2002) differentiated between distributed leadership as a numerical action and distributed leadership as a concertive action. As a numerical action, distributed leadership implies that within an organization leadership is diffused "among some, many, or maybe all of the members" (Gronn 2002, p. 429). Concertive action refers to a holistic way of construing distributed leadership that focuses on interactions that include spontaneous collaboration, intuitive working relationships and institutionalized practices. In his more recent developments of the leadership concept, Gronn (2009) argues for considering various leadership configurations. Practice shows that single, individual leaders and collective leadership forms exist 
simultaneously, and research must account for these hybrid forms of leadership. According to Gronn, distributed leadership solely focuses on collectively performed activities that are strongly interdependent, however, in practice, not all leadership tasks must be accomplished collectively (Gronn 2009). The hybrid form of leadership considers different combinations of individual and collective forms of distributed leadership.

Such an understanding of leadership conceives of leadership as grounded in activity rather than in a position or role. It does not mean that everyone is a leader or that formal positions are redundant, rather it maintains that each organizational member has leadership abilities able to convert into action if the situation requires (Spillane and Diamond 2007). Hence, distributed leadership considers spontaneous, emergent processes and non-fixed properties (Gronn 2002; Spillane et al. 2004; Woods et al. 2004) that constitute a dynamic organizational entity in which leadership tasks are distributed among the members of a given unit. Therefore, in place of leadership positions or roles, it becomes crucial to identify relevant leadership tasks. Taking this approach, Spillane et al. (2004) described concrete leadership tasks within the schoolcontext, which are distributed among teachers. We argue that there is a need to identify general leadership tasks that will be applicable beyond the educational sector to a broad range of organizations.

\section{Distributed Leadership Agency}

DLA extends Gronn's and Spillane's activity based approach of distributed leadership by designating general, concrete leadership tasks, which are derived from Yukl et al.'s (2002) three metacategories of general leadership behavior. As such, DLA encompasses task-oriented, relationship-oriented, and change-oriented leadership behavior (Jønsson et al. 2016), which are all applicable to various organizational settings. DLA represents an approach to leadership in which leadership functions are distributed to all employees who are willing to undertake such tasks and responsibilities, individually or collectively, including those without formal leadership authority. According to this definition, DLA may appear at various levels of an organization to flourish both vertically between levels and horizontally within the same level. DLA also encompasses interactions both among and between leader(s) and employees without formal leadership roles. Consequently, in addition to formalized and planned leadership tasks, DLA allows for and may encourage emergent, spontaneous, bottom-up initiatives.

Gronn and Spillane's descriptive approach is beneficial to define and describe DLA, however it neglects to investigate the effects of distributing leadership tasks. Mayrowetz (2008) claimed that although scholars had surveyed the impact of distributed leadership on several outcomes, they had not applied the promising activity approach. Recognizing this gap in the literature, within this study we attempt to combine Gronn and Spillane's activity perspective with a normative approach. Katz and Kahn (1978) acknowledged the competitive advantages of distributing leadership functions for an organization relatively early on "Those organizations in which influential acts are widely shared are most effective" (Katz and Kahn 1978, p. 332). They argued that employees' decision-making commitment would be strengthened and decision-making quality improved if team members spontaneously offered their influence for the purpose of reaching shared goals. In additional benefits, distributing leadership tasks to many employees can be expected to foster information as well as knowledge sharing, helps to improve communication among employees, and may even encourage employee personality development in the form of personal growth. Together with the use of 
a broad supply of human skills and competences, these characteristics should lead to greater satisfaction among employees, better performance and improved organizational effectiveness (D’Innocenzo et al. 2014; Mayrowetz 2008; Mehra et al. 2006; Peus and Frey 2009; Wang et al. 2014). Within shared-leadership research, there is much empirical evidence of the positive impacts on team performance and team effectiveness (cf. D'Innocenzo et al. 2014; Wang et al. 2014). However, the focus of shared-leadership scholars has been limited to the team or group level horizontally; it has not considered possible emergent bottom-up influences between hierarchical levels. Shared Leadership (Pearce and Conger 2003) in the broader conceptual space of employee involvement in organizational leadership (Wegge et al. 2010) uses peer-based influence and is discussed at the team level. Although various types of leadership can be shared (e.g. transformational, transactional, and empowering), DLA does not focus on different types of leadership but on concrete leadership activities. In Wegge et al.'s (2010) model, DLA can be considered as a form of Organizational Participation; this refers to processes in which power and influence as well as decision-making and responsibility are shared between all hierarchical levels. DLA asks to what extent each employee is actively engaged in leadership tasks, it does not ask how much he/she is involved in decision-making. Decision-making must be a collective process among all employees engaged in the related leadership tasks. The authority of control is social, which "...emerges from and shapes the kind and degree of coordination actors within the organization achieve in their practice and decision-making" (Woods 2016, p. 156). Organizational Democracy as the most comprehensive form of employee involvement of organizational leadership is an institutionalized form of employee participation and focuses only the organizational level (Wegge et al. 2010). Distributed leadership is not inherently democratic, however, it has democratic potential (Woods and Gronn 2009; Woods and Woods 2013). DLA with democratic potential focusses on the benefits for employees and society, which is crucial for humanistic businesses (e.g. Spitzeck et al. 2010; Melé 2009). By taking over leadership tasks, employees must engage with their colleagues, develop mutual understanding, share their knowledge and discuss conflicts. Such democratic processes protect human dignity (McCall 2001), lead to reciprocal respect within the company and can spill-over to employees' civic behaviors (Pateman 1970). Collective decision-making and leadership responsibilities can empower employees, increase their commitment, and enable them to recognize their influence at work to ultimately enhance self-efficacy and increase work motivation (Wegge et al. 2010).

Most empirical studies on distributed leadership have been conducted in the educational context. For example, interested in teachers' organizational commitment and job satisfaction, studies by Hulpia et al. (2012) show a positive relationship between these constructs and distributed leadership. Mascall et al. (2008) reported that only one form of distributed leadership (planful alignment) positively affected teachers' academic optimism, which included self and collective efficacy, trust, and organizational citizenship behavior. Few empirical studies on the impact of distributed leadership have been conducted beyond the school context, however, there is evidence of a positive relationship with employee self-efficacy (George et al. 2002; Jønsson et al. 2016), in a financial service firm higher sales were related to distributed forms of leadership (Mehra et al. 2006) and in the health-care context, distributed leadership has been related to service improvement (Fitzgerald et al. 2013). However, it should be noted that while these studies investigated distributed and shared leadership, the extent to which employees actively participated in leadership tasks in the sense of DLA, was not considered (except Jønsson et al. 2016). 


\section{Effects of Distributed Leadership Agency on Occupational Self-Efficacy}

Self-efficacy is a well-known construct in the psychological literature; it refers to the individual's conviction that he/she is able to execute the required behavior needed for the target outcome (Bandura 1997). In this sense, self-efficacy is the belief in oneself to cope with difficult tasks or situations, to successfully fulfil a given task, and as such, to be able to control environmental demands. Perceived self-efficacy strongly refers to personal action, control or agency (Scholz et al. 2002). In the organizational behavior literature, self-efficacy is an often investigated construct as it is known for its positive effects on work-related performance outcomes (e.g. Sitzmann and Yeo 2013), job satisfaction and wellbeing (e.g. Turgut et al. 2014).

With respect to the development of self-efficacy, Bandura $(1977,1997)$ offered three main sources to inform individuals of their personal efficacy: performance accomplishments (personal mastery experiences), vicarious experience and verbal persuasion. Applying Banduras' (1977) self-efficacy theory to the work context, Conger and Kanungo (1988) suggested empowerment as a process of enhancing self-efficacy beliefs. Empowerment as a relational approach means that managers share organizational resources with employees and give real power to them through participative management techniques (e.g. management by objectives, quality circles or delegating authority). The motivational approach refers to individuals' internal power needs, which are met when employees perceive that they have power or when they believe that they can appropriately cope with situations. Power in such a sense is a motivational disposition of the employee and managerial strategies that encourage the selfefficacy belief that will make employees feel more powerful. Conger and Kanungo (1988) advocate a motivational approach, arguing that it is more important to enable employees rather than to just delegate power. We assume that both approaches are not mutually exclusive, and that applying both will be most fruitful in empowering employees and strengthening their selfefficacy. Distributing leadership can be conceived as a management technique that fosters opportunities for employees to participate in decision-making (which is one empowering practice identified by Conger and Kanungo 1988), consequently delegating and relinquishing leadership functions to employees. Referring to the relational approach, this is real empowerment. Simultaneously, we assume that DLA increases employees' sense of on the job responsibility, and in this way, employees can test their efficacy (Conger and Kanungo 1988) with successful performance of leadership tasks leading to those enactive mastery experiences that are most decisive in developing self-efficacy (Bandura 1997). Adding empirical support to these theories, in a longitudinal study, George et al. (2002) found evidence of a positive relationship. Directly after finishing the program, nurses who participated in a shared leadership program reported increased self-confidence and effectiveness in addressing difficult situations. These feelings, which are attributed to self-efficacy, continued to develop over time. Mascall et al. (2008) cross-sectional study also directly investigated the effect of different patterns of distributed leadership on self-efficacy, this time on teachers. Although they confirmed a small positive correlation between the planful/aligned pattern of distributed leadership and teachers' self-efficacy, these patterns failed to detect active participation in leadership tasks. Axtell and Parker's (2003) study investigates a concept that is similar to DLA. In a two-wave design, they showed that employees who were actively involved in improvement activities, which can be seen as executing a leadership task, perceived higher self-efficacy over time. Jønsson et al. (2016) is the only study to date that has investigated the effect of employees' DLA on occupational self-efficacy. With a cross-sectional design in a 
hospital context they found evidence of a positive relationship between DLA and self-efficacy. Based on the theoretical considerations described above, and on the reported empirical evidence, the following hypothesis is presented:

\section{Hypothesis 1: DLA is positively related to occupational self-efficacy.}

\section{Perceived Autonomy as an Antecedent of Distributed Leadership Agency}

In the distributed leadership literature, scholars generally emphasize organizational culture and organizational structure as the main drivers for the development of distributed leadership (Leithwood et al. 2007; Murphy et al. 2009; Woods et al. 2004). In particular, flat organizational structures that provide opportunities for collaboration among employees encourage the distribution of leadership (Leithwood et al. 2007). One important characteristic of such flat organizational structures is a high amount of autonomy. In the distributed leadership concept, Woods et al. (2004) also point to control and autonomy as crucial factors.

According to Hackman and Oldham (1975, p. 162), autonomy is: "The degree to which the job provides substantial freedom, independence, and discretion to the employee in scheduling the work and in determining the procedures to be used in carrying it out." We apply Hackman and Oldham's concept of autonomy, and focus on employees' individual perception of autonomy. Specifically, we are interested in the opportunities for autonomy as perceived by the individual and which opportunities the employees perceive - not if they actually use these opportunities. As usage of participation opportunities concerns employees' actual participation in leadership tasks, we consider this to be the scope of DLA. This rationale follows Hanna et al.'s (2014) suggestion that in leadership research it is crucial to separate the antecedents from leaders' behaviors. To assume a causal relationship between autonomy and DLA we draw upon Archer's (1982) analytical dualism. Archer (1982) proposed that structural properties are timely prior to actions, that structures are constraining and/or facilitating action and that it takes time to change any structural property. However, action takes place within that context, and effective actions are able to influence prior structures. Structural properties are rules and resources (Archer 1982) and autonomy can be viewed as an important organizational rule and resource that should be perceived similarly among employees within a company. As an organizational, contextual condition, autonomy enables employees to attempt new ways of accomplishing their work, to take initiative and participate in leadership tasks. Hence, we assume that an individual's autonomy - which should be similar to collectively perceived autonomy - as a feature of organizational structures is likely to facilitate employee activity in leadership tasks whereas bureaucratic and strong hierarchical structures may hinder active participation in leadership functions.

Empirical research on antecedents of distributed leadership forms is scarce. Two studies have investigated the impact of institutionalized democratic structures on employees' perceived participation in decision-making on operational, tactical, and strategic issues within organizations (Unterrainer et al. 2011; Weber and Unterrainer 2012). Both studies found strong positive relationships between democratic company structures and employees' perceived activity in organizational decision-making. Two other studies have confirmed the positive effects of forms of vertical leadership (transformational, empowering, and gatekeeping leadership) on shared leadership (Hoch 2013; Ishikawa 2012). Team characteristics such as team integrity, team collectivism, and intragroup trust, as well as internal team environment, are also empirically supported determinants of shared leadership (Carson et al. 2007; Daspit et al. 2013; Small and Rentsch 2010). 
Nevertheless, no quantitative empirical study investigating the impact of individually perceived autonomy on DLA has yet been conducted. There are some qualitative accounts that indicate antecedents likely to develop distributed leadership. For example, Fitzgerald et al. (2013) conducted an extensive study within the health-care sector, and found that several positive combinations of contextual features facilitated distributed leadership; with other factors, autonomy was one of the positive features that enabled distributed leadership. Another qualitative study (Leithwood et al. 2007) showed that collaborative structures and employee autonomy contributed to the distribution of leadership functions. Murphy et al. (2009) investigated the implementation of distributed leadership in a US middle school over a period of three years. With respect to organizational structure, results indicated that the following factors - providing an individual teacher with the autonomy to participate in leadership tasks, building up forums in which leadership can emerge, and when teachers were allowed to decide how they accomplished and implemented their leadership tasks - all fostered the development of distributed leadership. In summary of the above literature review, taking into consideration the few but consistent results of empirical studies on related concepts of DLA, and following Archer's (1982) theory of analytical dualism on structure and agency, we propose the following hypothesis:

\section{Hypothesis 2: Individually perceived autonomy is positively related to DLA.}

\section{The Mediating Role of Distributed Leadership Agency on the Autonomy-Occupational Self-Efficacy Relationship}

As previously mentioned, based on Archers' (1982) structure-agency approach, we consider perceived autonomy as a structural feature that enables employees' active participation in leadership tasks. We also discussed, according to Bandura (1997), that actively participating in leadership tasks offers employees opportunities to practice meaningful mastery experiences that foster the development of self-efficacy. However, what about the relationship between perceived autonomy and self-efficacy? The positive effect of autonomy on an individual's selfefficacy is well supported in the literature (e.g. Axtell and Parker 2003; Parker 1998). Parker (1998); Axtell and Parker (2003) argued that, through autonomy, employees experience more personal control over their environment, and that perceived control is a fundamental determinant of self-efficacy. Kohn and Schooler (1973) investigated the extent to which conditions of work - autonomy being one of those conditions - influenced employee values and psychological orientations at work. Among others, they found that the more freedom employees experienced on the job, the greater their self-efficacy. While they assumed a reciprocal relationship between conditions and personal change, they concluded that the reciprocity is not equal: "In all cases, job affects man more than man affects job" (Kohn and Schooler 1973, p. 114), which is in accordance with Archers' (1982) structure-agency approach. In longitudinal studies, both Mortimer and Lorence (1979) and Parker (1998) provide empirical support to the socialization effect of work experiences, especially in relation to work autonomy on personal efficacy.

These studies investigated the direct effect of autonomy or control on employees' selfefficacy, however, they neglected to consider potential mediator variables. Gecas (1989) suggests autonomy as an occupational condition capable of enabling an "efficacious action" that is "conducive to the development of self-efficacy" (Gecas 1989, p. 304). According to this 
rationale, we assume that participating in leadership tasks is one such efficacious action with which employees can increase their knowledge, and through which they receive control over certain situations that in turn may lead to a higher self-efficacy. Referring to Archer's (1982) morphogenetic cycle, we propose that as a structural feature, perceived autonomy encourages employee participation in leadership tasks, and that continued participation will increase occupational self-efficacy. Furthermore, higher occupational self-efficacy may alter the perception of prior existing autonomy structures within the organization, to subsequently again influence employee participation in leadership tasks. We therefore hypothesize that DLA is one mechanism to explain the positive relationship between perceived autonomy and employees' self-efficacy at work.

Hypothesis 3: The positive relationship between individually perceived autonomy and occupational self-efficacy is partially mediated by DLA.

\section{Method}

\section{Sample and Procedure}

The present study was conducted in a Danish municipality that intended to introduce distributed leadership practices in the center that dealt with various public services for citizens from the age of $0-18$ years (and their parents). The services include pedagogic psychology and counselling, child and family counselling and healthcare. Accordingly, employees are pedagogics/teachers, psychologists, social workers, ergo therapists, consultants and administrative staff. Data was collected via an online survey and respondents were recruited through their email address, provided by the contact person in the municipality. We assured participants complete confidentiality and anonymity, although recording e-mail addresses was necessary to help ensure data was matched from the first to the second wave. Data was first collected in August 2013 (T1) and the second wave occurred in March 2014 (T2), before the first interventions on implementing distributed leadership commenced. The length of the time lag is always critical in longitudinal research, however in our case, we were restricted by the natural setting as the municipality was scheduled to begin interventions before the end of March 2014. Even if interventions had not begun before the second wave, changes in DLA and occupational self-efficacy may occurred within those seven months. The municipality followed a bottom-up approach of implementation, and between T1 and T2 employees in the affected departments discussed with management if they wanted to participate in the distributed leadership project. These discussions and making a joint decision about the participation are leadership functions that were already distributed to the employees, and therefore likely affected their evaluation. At T1 we invited 150 employees to participate and 126 responded; nine questionnaires had to be deleted owing to missing values on entire scales, leaving a total sample of 117 at T1 (78\% response rate). At T2, we asked 145 employees to participate, 108 answered and 19 were deleted due to missing values on entire scales, leaving a sample of $n=89$ at T2 (61\% response rate). Data matching between responses at T1 and at T2 led to a final sample of 67 employees who participated at both measurement points. This matched sample included less than 10\% missing values per person (according to Kline 1998), which were imputed (expectation-maximization algorithm) using NORM software (Graham et al. 2003) to prevent bias caused by not having completely random missing data processes. Of the 
final sample, the average employee was female (91\%), 47 years old (range $=25-63$ years), with 10 years of job tenure (range $=1-45$ years). The range in education was substantially narrow, $76 \%$ finished high school or had a bachelor's education, while $24 \%$ had a master's or $\mathrm{PhD}$ degree. A relatively high percentage of the sample $(42 \%)$ had been formerly or is now actively, executing employee representative tasks (e.g. shop steward duties or a member of the work council) at a company.

To check for a systematic attrition rate, we conducted independent sample t-tests and chisquare-tests for each variable. Of the initial 117 employees, 50 did not participate in T2. The results of the analysis indicated that employees who participated in T1 and T2 $(n=67)$ had significantly higher initial values in DLA $(t(115)=-2.65, p=.009, d=-0.50)$ and occupational self-efficacy $(t(115)=-2.96, p=.004, d=-0.56)$ than those employees who did not respond at T2 $(n=50)$. These results suggest that the initial sample of 117 employees differs from the final sample of 67 with respect to the DLA baseline and occupational selfefficacy, but not to perceived autonomy, age, gender, and representative tasks.

\section{Measures}

Perceived Autonomy We assumed autonomy to be a structural feature that would result in a shared perception of autonomy among all organizational members. However, we assessed perceived autonomy on the individual level, using the self-determination dimension of Spreitzer's (1995) empowerment measure. Spreitzer (1995) derived the three selfdetermination items from Hackman and Oldham's (1980) autonomy scale. The interrater agreement among employees indicated that their perception of autonomy is very similar $\left(r_{\mathrm{wg}}=.82\right.$ for $\mathrm{T} 1 ; r_{\mathrm{wg}}=.84$ for $\left.\mathrm{T} 2\right)$ and justifies the usage of individually perceived autonomy. A sample item is: "I can decide on my own how to go about doing my work." Responses were recorded on a five-point scale ranging from 1 (strongly disagree) to 5 (strongly agree). Cronbach alphas for the measure were $\alpha=.90$ at T1 and $\alpha=.91$ at T2.

Distributed Leadership Agency We assessed individual participation in leadership tasks with seven items from Jønsson et al.'s (2016) measure of DLA. This scale is based on Yukl et al. (2002) three meta-categories of leadership behavior (task, relations, and change), which is validated in the hospital context. It requests active participation from employees' on task-, relations- and change-oriented leadership functions within their unit. As recommended by Jønsson et al. (2016), we calculated these dimensions as one overall composite. Sample items are: "Have you had the responsibility for organizing work tasks at your unit?" (task-dimension); "Have you participated in organizing activities about the development of competences for your colleagues?" (relations-dimension); "Have you participated in setting goals for the development of your unit?" (change-dimension). Responses were recorded on a five-point scale ranging from $1=$ not at all to $5=$ very much. Cronbach's alpha was $\alpha=.93$ at T1 and $\alpha=.91$ at T2.

Occupational Self-Efficacy We measured occupational self-efficacy with the validated eight-item version from Schyns and von Collani (2002). This measure was specific to the work domain and assesses employee confidence that they will be able to fulfill various tasks in their job and cope with problems at work. A sample item is: "When I am confronted with a problem in my job, I can usually find several solutions." Employees responded using a fivepoint scale, ranging from 1 (strongly disagree) to 5 (strongly agree). Cronbach alphas were good at both time points (T1: $\alpha=.86$; T2: $\alpha=.90$ ). 
Control Variables We considered gender $(0=$ female, $1=$ male $)$, age and representative function $(0=$ no representative function, $1=$ having a representative function $)$ as control variables.

We administered all measures in Danish. The DLA scale was originally constructed in Danish, however, the perceived autonomy and occupational self-efficacy scales were originally formulated in English, translated to Danish and then back to English (Brislin 1986).

\section{Analytical Approach}

The DLA measure is conceptualized as an employee's individual participation in leadership tasks in their unit. We were therefore interested in employees' individual level of DLA and not in their unit or department level. The sample only included three departments, which is not enough for multi-level analysis. Additionally, we computed the ICC1 for DLA at T1 and T2. The ICCs were low to very low (T1: ICC1 $=0.050$; T2: ICC1 $=0.003)$, thus supporting our decision to analyze DLA at the individual level (LeBreton and Senter 2008).

We tested all proposed hypotheses (total, direct, and indirect effects) with the Process tool in IBM SPSS 21.0, developed and provided by Hayes (2013). Process applies bootstrapping that does not assume the assumption of normality, which is recommended in small samples and for testing indirect effects (Hayes 2013). We conducted 5000 bootstrap samples for biascorrected $95 \%$ bootstrap confidence intervals. All variables were standardized before entering into the regression equation, and we applied an autoregressive model (Taris and Kompier 2006) for testing a half-longitudinal mediation with two data waves. Accordingly, DLA at T2 was the mediating variable, and occupational self-efficacy at T2 the dependent variable, controlling for DLA at T1 and occupational self-efficacy at T1.

\section{Results}

Prior to testing the proposed hypothesis, we conducted confirmatory factor analyses (CFA) to test the factor structure of the three variables at each measurement time; we used Mplus v.7.11. We applied a Maximum Likelihood Robust (MLR) estimation of model fit, utilizing Hu and Bentler's (1998) recommendations for model fit indices (RMSEA $<0.10$, and CFI/TLI $>0.90$ ). The threefactor model obtained good fit for T1 $\left(\chi^{2}(132)=161.96, p=.04\right.$, RMSEA $=.04$, CFI $=.97$, $\mathrm{TLI}=.97)$ and acceptable fit for T2 $\left(\chi^{2}(131)=186.97, p<.01\right.$, RMSEA $=.08$, CFI $=.92$, $\mathrm{TLI}=.91$; one error correlation was added to occupational self-efficacy). Contrary to the threefactor model, a Satorra-Bentler scaling corrected chi-square difference test (Satorra and Bentler $1999)$ indicated that the one-factor model did not fit the data well at $\mathrm{T} 1\left(\chi^{2}(135)=560.04\right.$, $p<.01$, RMSEA $=.16$, CFI $=.57$, TLI $\left.=.51 ; \Delta \chi^{2}(3)=298.51, p<.01\right)$, and at T2 $\left(\chi^{2}\right.$ $(134)=500.65, p<.001$, RMSEA $=.20, \mathrm{CFI}=.50, \mathrm{TLI}=.43 ; \Delta \chi^{2}(3)=193.03, p<.01$; for comparison, the same residual as in the three-factor model was correlated). For further evidence of discriminant validity we calculated the average variance extracted (AVE) for each latent construct at T1 and T2 (Fornell and Larcker 1981). The AVE measures the explained variance of the latent construct and should be above 0.50 . Additionally, the AVE's square root of each construct should be larger than the zero-order correlation with any other latent construct in the model (Gefen and Straub 2005). AVEs and their square roots are listed in Table 1. Only the AVE of occupational self-efficacy at $\mathrm{T} 1$ was below the cut-off value of 0.50 . As all other zero-order correlations were less than the square root of the AVE, there is evidence of discriminant validity (Table 1). 
Table 1 Bivariate correlations and average variance extracted analysis for T1 and T2

\begin{tabular}{|c|c|c|c|c|c|c|c|c|c|}
\hline & & 1 & 2 & & 4 & 5 & 6 & $\mathrm{AVE}_{\mathrm{T} 1}$ & $\begin{array}{l}\text { AVE square } \\
\operatorname{root}_{\mathrm{T} 1}\end{array}$ \\
\hline \multirow{8}{*}{$\begin{array}{l}1 . \\
2 . \\
3 . \\
4 . \\
5 . \\
6 .\end{array}$} & Gender & & -.02 & -.05 & .03 & .19 & -.06 & & \\
\hline & Age & .06 & & $.26 *$ & -.06 & .03 & .08 & & \\
\hline & Representative function & .02 & $.28^{* *}$ & & .19 & .09 & .20 & & \\
\hline & Individually perceived autonomy & .09 & .01 & .03 & & $.31 *$ & $.37 * *$ & .75 & .87 \\
\hline & DLA & .13 & $.42 * *$ & $.25 * *$ & $.20 *$ & & $.32 * *$ & .64 & .80 \\
\hline & Occupational self-efficacy & -.08 & $.37 * *$ & $.21 *$ & $.25 * *$ & $.38 * *$ & & .44 & .66 \\
\hline & $\mathrm{AVE}_{\mathrm{T} 2}$ & & & & .77 & .59 & .53 & & \\
\hline & AVE square $\operatorname{root}_{\mathrm{T} 2}$ & & & & .88 & .77 & .73 & & \\
\hline
\end{tabular}

Values for T1 $(n=117)$ are shown below the diagonal, for T2 $(n=67)$ above the diagonal. * $p<.05, * * p<.01$

\section{Cross-Sectional Testing for Mediation}

We ran a simple process model (Model 4; Hayes 2013) to test all hypotheses at both time points separately. We defined individually perceived autonomy as a predictor, DLA as a mediator and occupational self-efficacy as an outcome variable, controlling for gender, representative function and age. Cross-sectional results are depicted in Table 2. The direct effects show support for Hypothesis 1: DLA was positively related to occupational selfefficacy at both measurement time points (T1: $\beta=.23, p=.014$; T2: $\beta=.25, p=.023$ ). In Hypothesis 2 we proposed that individually perceived autonomy would be positively related to DLA; this was supported at both time points (see "a paths"; T1: $\beta=.19, p=.009$; T2: $\beta=.30$, $p=.020$ ). Finally, in line with Hypothesis 3 , indirect effects confirmed a mediational effect of DLA on the positive relationship between individually perceived autonomy and occupational self-efficacy (T1: $\beta=.04,95 \%$ CI $[0.01,0.10]$; T2: $\beta=.07,95 \%$ CI $[0.01,0.21]$ ). Direct effects indicated a partial mediation as the effect of individually perceived autonomy to occupational self-efficacy remained significant at both time points $(\mathrm{T} 1: \beta=.21, p=.010$; T2: $\beta=.27, p=.030)$. At T1, age was the only control variable positively related to DLA $(\beta=.37, p<.001)$ and occupational self-efficacy $(\beta=.26, p=.010)$. At $\mathrm{T} 2$, no control variables were related to the mediating or outcome variable. Overall, individually perceived autonomy, DLA and the control variables explained $26.62 \%$ of variance in occupational selfefficacy at $\mathrm{T} 1, F(5,111)=7.33, p<.001$, and $21.09 \%$ of variance in occupational self-efficacy at $\mathrm{T} 2, F(5,61)=4.25, p=.002$.

\section{Cross-Lagged Testing for Mediation}

Although the results of cross-sectional testing provided support for the hypothesized relationships, testing these relationships over time provides stronger evidence for the direction of the hypothesized relations. Cross-lagged bivariate correlations for T1 and T2 with the matched sample $(N=67)$ indicated positive, medium effects between individually perceived autonomy, DLA, and occupational self-efficacy over time (Table 3).

To test our hypotheses, we again ran a simple process model (Model 4; Hayes 2013) specifying individually perceived autonomy at T1 as a predictor, DLA at T2 as a mediator and occupational self-efficacy at T2 as a criterion variable. The control variables: gender, age and representative function, were accounted for in the regression model as covariates in addition to DLA at T1 and occupational self-efficacy at T1. Controlling for both prior levels of the 


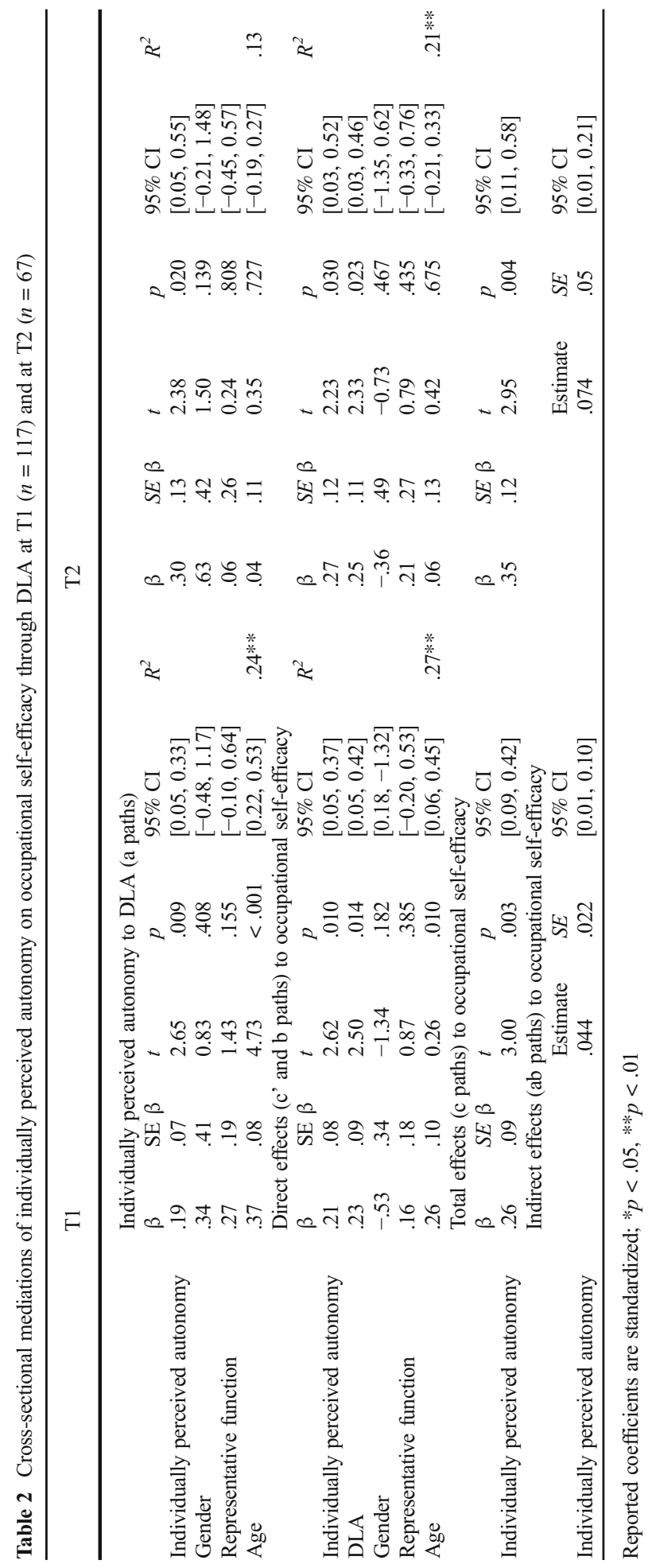




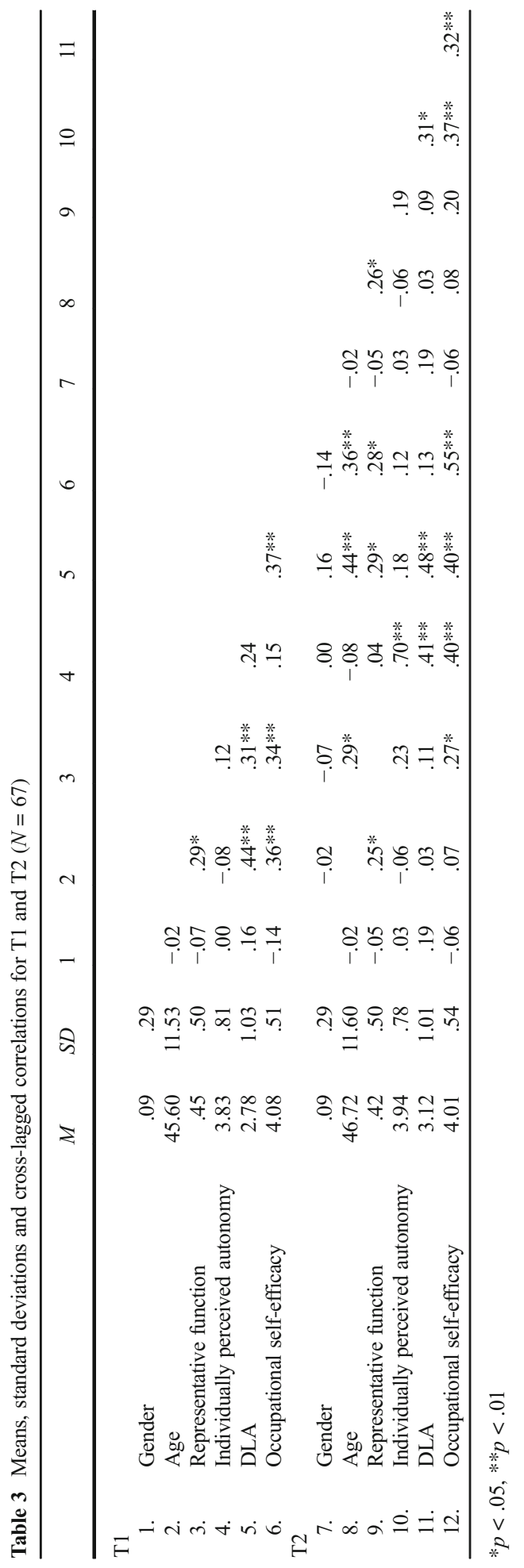


mediator (DLA), and prior levels of the outcome (occupational self-efficacy), is referred to as an autoregressive model (Cole and Maxwell 2003; Taris and Kompier 2006). Table 4 demonstrates the results of the autoregressive model, with the direct effect supporting Hypothesis 1 over time: DLA at T1 significantly predicted occupational self-efficacy at T2 $(\beta=.22, p=.05)$ when occupational self-efficacy at T1 was controlled for. Consistent with Hypothesis 2, individually perceived autonomy at $\mathrm{T} 1$ was positively related to DLA at T2 $(\beta=.29$, $p=.03$ ) when DLA at T1 was controlled for (see "a paths"). Inspecting the indirect effect of individually perceived autonomy on occupational self-efficacy $(\beta=.02,95 \%$ CI $[-0.03$, $0.11]$ ), Hypothesis 3 was not supported. DLA at T2 did not mediate the positive relationship between individually perceived autonomy at $\mathrm{T} 1$ and occupational self-efficacy at $\mathrm{T} 2$. However, there was a significant positive direct effect of individually perceived autonomy at $\mathrm{T} 1$ to occupational self-efficacy at $\mathrm{T} 2(\beta=.23, p=.05)$ beyond prior levels of occupational self-efficacy (T1). Figure 1 illustrates the results of the autoregressive model, with the overall model (direct effects) explaining $46.44 \%$ of the variance in occupational self-efficacy at T2.

To further support the claim of directionality in our significant relationships, we ran two alternative autoregressive models. Alternative model 1 defined individually perceived autonomy at T1 as a predictor, occupational self-efficacy at T2 as a mediator and DLA at T2 as a criterion variable. In line with our model, individually perceived autonomy at T1 predicted DLA at T2 $(\beta=.29, p=.03)$ and occupational self-efficacy at $\mathrm{T} 2(\beta=.25, p=.02)$ when controlling for prior levels of DLA and occupational self-efficacy. However, occupational selfefficacy at T1 did not predict DLA at T2 $(\beta=-.06, p=.68)$. In our hypothesized model, DLA at $\mathrm{T} 1$ predicted occupational self-efficacy at T2. As such, results support our claim of directionality, indicating that DLA is timely prior to occupational self-efficacy and not the inverse. Alternative model 2 specified DLA at T1 as a predictor, occupational self-efficacy at

Table 4 Cross-lagged mediation of individually perceived autonomy on occupational self-efficacy through DLA $(N=67)$

\begin{tabular}{|c|c|c|c|c|c|c|}
\hline & \multicolumn{5}{|c|}{ Individually perceived autonomy T1 to DLA T2 (a paths) } & \multirow[b]{2}{*}{$R^{2}$} \\
\hline & $\beta$ & $S E \beta$ & $t$ & $p$ & $95 \% \mathrm{CI}$ & \\
\hline Individually perceived autonomy $\mathrm{T} 1$ & .29 & .13 & 2.24 & .03 & {$[0.03,0.55]$} & \\
\hline DLA T1 & .47 & .16 & 2.93 & .01 & {$[0.15,0.79]$} & \\
\hline Occupational self-efficacy T1 & -.02 & .12 & -0.16 & .87 & {$[-0.27,0.23]$} & \\
\hline Gender & .38 & .43 & 0.88 & .38 & {$[-0.48,1.24]$} & \\
\hline Representative function & -.02 & .23 & -0.08 & .94 & {$[-0.48,0.45]$} & \\
\hline \multirow[t]{3}{*}{ Age } & -.15 & .13 & -0.16 & .87 & {$[-0.27,0.23]$} & $.36^{* *}$ \\
\hline & \multicolumn{5}{|c|}{ Direct effects (c' and b paths) to occupational self-efficacy T2 } & \\
\hline & $\beta$ & $S E \beta$ & $t$ & $p$ & $95 \% \mathrm{CI}$ & $R^{2}$ \\
\hline Individually perceived autonomy $\mathrm{T} 1$ & .23 & .11 & 2.02 & .05 & {$[0.00,0.45]$} & \\
\hline Occupational self-efficacy T1 & .48 & .10 & 4.67 & $<.01$ & {$[0.28,0.69]$} & \\
\hline DLA T1 & .22 & .11 & 2.02 & .05 & {$[0.00,0.44]$} & \\
\hline DLA T2 & .07 & .11 & 0.63 & .53 & {$[-0.16,0.30]$} & \\
\hline Gender & -.14 & .37 & -0.37 & .71 & {$[-0.87,0.60]$} & \\
\hline Representative function & .06 & .24 & 0.26 & .80 & {$[-0.41,0.53]$} & \\
\hline \multirow[t]{3}{*}{ Age } & -.19 & .14 & -1.33 & .19 & {$[-0.47,0.09]$} & $.46 * *$ \\
\hline & \multicolumn{5}{|c|}{ Total effect (c path) to occupational self-efficacy } & \\
\hline & $\beta$ & $S E \beta$ & $t$ & $p$ & $95 \% \mathrm{CI}$ & \\
\hline \multirow[t]{3}{*}{ Individually perceived autonomy $\mathrm{T} 1$} & .25 & .10 & 2.51 & .02 & {$[0.05,0.45]$} & \\
\hline & \multicolumn{5}{|c|}{ Indirect effect (ab path) to occupational self-efficacy } & \\
\hline & & & Estima & $S E$ & $95 \% \mathrm{CI}$ & \\
\hline Individually perceived autonomy $\mathrm{T} 1$ & & & .02 & .04 & {$[-0.03,0.11]$} & \\
\hline
\end{tabular}

Reported coefficients are standardized; $* p<.05$, ** $p<.01$ 


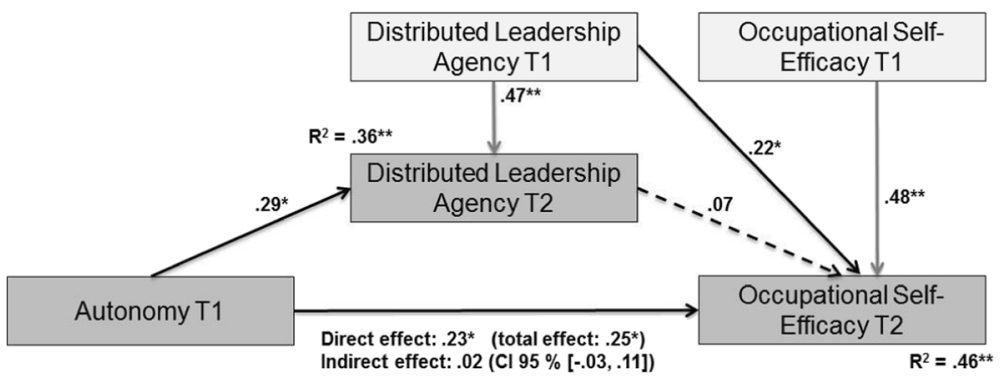

Fig. 1 The cross-lagged mediation model $(N=67)$. Reported coefficients are standardized; * $p<.05, * * p<.01$

$\mathrm{T} 2$ as a mediator, and individually perceived autonomy at T2 as a criterion variable. DLA at T1 again significantly predicted occupational self-efficacy at $\mathrm{T} 2(\beta=.25, p=.02)$ when controlling for occupational self-efficacy at T1. However, it did not predict individually perceived autonomy at T2 $(\beta=-.05, p=.63)$ when controlling for individually perceived autonomy at T1. Furthermore, the direct effects reveal that occupational self-efficacy at T1 did not predict individually perceived autonomy at $\mathrm{T} 2(\beta=-.08, p=.55)$ when controlling for individually perceived autonomy at T1 (Table 5).

\section{Discussion}

The current two-wave study investigated the concept of DLA and applied a normative approach by examining individual autonomy as an antecedent, occupational self-efficacy as an outcome and DLA as the mediator of the autonomy-self-efficacy relationship in the organizational context. Findings indicated that DLA is positively related to occupational self-efficacy cross-sectionally and over time. This suggests that employees will perceive self-efficacy if they can consistently participate in leadership tasks. Additionally, in the cross-sectional as well as cross-lagged analyses, autonomy was an important antecedent for DLA. Autonomy as a contextual condition provides employees with the opportunity and freedom to take initiative, to participate in leadership functions and to execute leadership tasks. Although the mediating role of DLA on the autonomy-self-efficacy relationship was supported cross-sectionally at both time points, it should be noted that it was not significant in the cross-lagged analyses. However, the autoregressive model revealed a direct effect of individually perceived autonomy on occupational self-efficacy over time. Overall, the cross-lagged analyses underscored our hypothesized relationships, even though the mediation effect was not significant. Consequently, these half-longitudinal results provide support for a first nomological framework of DLA.

\section{Theoretical Implications}

Our study contributes to the distributed leadership research in several ways. To date, few empirical studies have investigated distributed leadership, most have been limited to the school context and have used cross-sectional designs that could not incorporate an activity approach to the operationalization of distributed leadership. We investigated a Danish municipality that with their employees decided to introduce distributed leadership processes. These processes are based upon delegation, emergence and employee willingness to execute leadership 


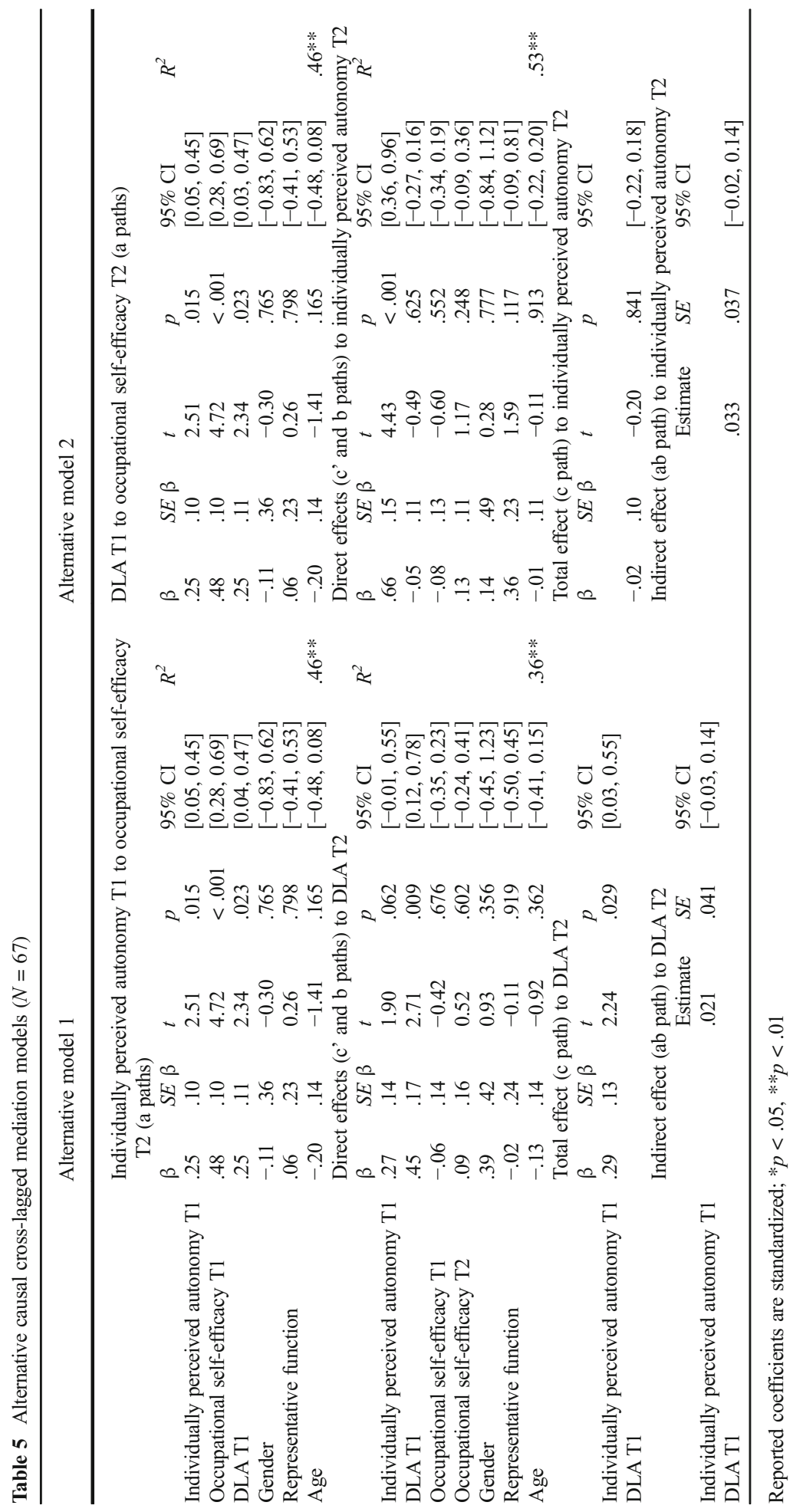


functions. In accordance with an agency-activity perspective, we measured DLA by asking for each employee to actively participate in leadership tasks. Additionally, we surveyed employees at two times in order to investigate time-related effects of the hypothesized relationships.

Results underline the importance of structural working conditions for employees to engage in leadership tasks. High perceived autonomy is positively related with active participation in leadership functions. Individually perceived autonomy is a working condition and a structural feature that offers employees the opportunity and freedom to try new ways of accomplishing their work - for example, to participate or not in leadership tasks. Archer's (1982) analytical dualism and Kohn and Schooler's (1973) socialization effect highlight this relationship insofar as considering a time perspective. Structural properties are timely prior to actions, and can help to constrain or facilitate actions (Archer 1982); the socialization effect in organizations assumes that working conditions impact on individual work behavior more than individual behavior influences working conditions (Kohn and Schooler 1973); cross-lagged results of the present study support both theoretical approaches. Individually perceived autonomy is timely prior to DLA; the alternative model further supported this directionality as DLA at T1 did not predict individually perceived autonomy at $\mathrm{T} 2$.

Congruent with empirical studies that have investigated the relationship between distributed forms of leadership and self-efficacy (Axtell and Parker 2003; George et al. 2002; Jønsson et al. 2016; Mascall et al. 2008), our results support a positive relationship between DLA and occupational self-efficacy. Adding important information to the literature, our two-wave design allows us to draw the conclusion that DLA is timely prior to occupational self-efficacy. By successfully participating in leadership tasks, employees may perceive the fundamental mastery experiences (Bandura 1997) conducive for the development of self-efficacy at work. Specifically, positive mastery experiences or efficacious actions (acc. to Gecas 1989) improve employees' knowledge, and through their experiences they receive control over situations that in turn lead to higher self-efficacy.

With respect to the proposed mediating effect of DLA on the positive relationship between individually perceived autonomy and occupational self-efficacy, results support a partial crosssectional mediation at both time points. In our opinion, a partial mediation is convincing since we assumed that autonomy enables not only participating in leadership tasks as efficacious action that leads to an enhanced self-efficacy. Of course, it should also be considered that many possibilities beyond leadership tasks will exist for employees to act efficaciously at work, and which are also fostered by autonomy and result in higher self-efficacy. For example, performing new tasks or trying new ways of accomplishing traditional work tasks could be expected to increase knowledge and skills, to consequently raise self-efficacy. In the crosslagged analyses of the present study, the proposed mediation effect was not evident; the small sample size could have been a factor. Testing hypotheses with small sample sizes runs the risk of not detecting significant effects (Type II errors). The half-longitudinal design (surveying all variables only twice) is another potential factor. Using at least three measurement time-points would have improved the accuracy of the mediation tests. We analyzed both the mediator and the dependent variable at $\mathrm{T} 2$ and the insignificant relationship may have been partly due to the lack of time that DLA needs for leading to higher self-efficacy. The significant effect of DLA at $\mathrm{T} 1$ on occupational self-efficacy at T2 supports this theory. Additionally, the significant direct effect of individually perceived autonomy at T1 on occupational self-efficacy at T2, indicates that autonomy is timely prior to self-efficacy. The alternative models supported our proposed directionality as the reversed paths were not significant. 
Overall, the results of all cross-lagged paths provide causal hints that are in line with Archer's (1982) morphogenetic cycle. Structural properties are timely prior to actions, as they will either constrain or facilitate an action. Autonomy as a feature of organizational structures helps to facilitate employee participation in leadership tasks. Participating in leadership tasks over an extended period would then in turn be expected to increase occupational self-efficacy, although restricted by a two-wave design, in the present study we could not test the entire causal spiral. We were also not able to further test whether higher occupational self-efficacy alters the perception of prior existing autonomy structures over time, and whether they could then subsequently influence participation in leadership tasks. However, we demonstrated time-related effects that are not in line with Spreitzer's (1995) conceptualization of empowerment. Spreitzer (1995) operationalized autonomy and competence as one overall construct, and the competence dimension is very similar to occupational self-efficacy. Our results however, indicated that autonomy is timely prior to self-efficacy, they are also contrary to the conclusions of Seibert et al. (2011) who suggested that the strong intercorrelations between the empowerment subdimensions indicate a simultaneous occurrence. The results of the present study demonstrate that at least the two dimensions of autonomy and competence/self-efficacy may be separated by time.

Furthermore, we are convinced that DLA might be a fruitful concept in humanistic management research, which instead of profit-maximization, focusses on human dignity and employee well-being. Although several humanistic management scholars support individual leadership styles (e.g. transformational, authentic, or empowering leadership) to protect employee fundamental human needs (Dierksmeier 2016; Pereira Lopes et al. 2009; Peus and Frey 2009; Pirson 2009; Pirson and Lawrence 2010), shared leadership perspectives, such as DLA, remain rare in humanistic management literature. Dierksmeier (2016, p. 26) pointed to the humanistic potential of self-management oriented leadership styles, which relate to DLA because boundaries between leaders and followers become blurred and such styles "... rather advocate for the responsibility of all and the dominance of no-one". In a similar vein, Maak and Pless (2009) suggested that successful responsible leaders make their followers into leaders. However, beyond the above approaches, by its very definition DLA represents a leadership perspective in which leadership functions are distributed to all employees (with and without formal leadership authority); the consequence is that followers become leaders and leaders become followers. DLA pursues a bottom up strategy where employees who are willing, individually or collectively take over leadership tasks and responsibilities. Additionally, DLA is appropriate for several organizational practices that in their principlebased model of leadership Peus and Frey (2009) recommended for facilitation of employee development (e.g. transparency through information and communication, participation and autonomy, constructive feedback, personal growth). Although these principles are not exclusive to single leaders, if leadership were to be distributed among several or all organizational members, they may become much more integral components of organizational performance. The present study indicates that DLA has the potential to serve employees' personal development by fostering self-efficacy. Considering the humanistic potential of DLA, it is a worthy addition to humanistic management discussions.

\section{Practical Implications}

The findings of the present study have several implications for practice. First, indications of positive consequences for employees demonstrate that DLA is a desirable leadership perspective. It increases employees' occupational self-efficacy, which is known to positively affect 
work-related performance (e.g. Sitzmann and Yeo 2013), employee job satisfaction and wellbeing (e.g. Turgut et al. 2014). However, if management wants to introduce distributed leadership structures, several aspects must be considered. As the results of the present study demonstrate, individually perceived autonomy is a precondition for DLA. Therefore, management must provide appropriate structures that enable employees to participate in both work and leadership tasks, such as for granting employees time for meetings to share their knowledge, for trying new ways of accomplishing tasks, and by supplying courses and training. Employees need to become competent in teamwork, cultivate a collective orientation, social skills, and complementary knowledge (Yammarino et al. 2012), which is true for informal emergent leaders as well as for formal, existing leaders. Both must be prepared before distributed leadership forms can be implemented in a restructuring process. Formal leaders must be willing to delegate leadership functions, and as such, to share power and responsibilities with employees. Simultaneously, they must also be able to stimulate employees to take leadership responsibilities (cf. Maak and Pless 2009). Management must be aware that the delegation of leadership tasks and stimulating emergent bottom-up processes of DLA is real employee empowerment (cf. Conger and Kanungo 1988). In our opinion and in line with the humanistic management paradigm (e.g. Dierksmeier 2016; McCall 2001; Spitzeck et al. 2009), it is important that employees do not only feel that they are empowered, but that they obtain real power by actively executing leadership tasks and by participating in decision-making processes. Real employee empowerment not only has consequences for work behavior, but also at the wider societal level. Although distributed leadership is not inherently democratic, it offers democratic potential that lays the groundwork for democratic leadership (Gronn 2008; Woods and Gronn 2009). Conversely, organizational democracy, which may extend to employee-owned and self-governed enterprises, may be the most comprehensive form of DLA (Wegge et al. 2010). Studies have shown that democratic company structures are positively related with employee ethical value orientation and democratic engagement orientation towards society (Unterrainer et al. 2011; Weber et al. 2009). In addition to the potential positive effects of a democratic approach of DLA, there are concerns that distributed leadership is merely a new way to deliver top-down policies (Harris 2013). There is the potential for DLA to be misused as the simple delegation of tasks without providing employees substantial influence, rather a pseudo-participation a (Heller 2003). Long-term, such practices could be expected to lead to employee disillusionment as well as to future resistance and cynicism against DLA and similar participation projects (McCall 2001; Strauss 2006).

\section{Strengths, Limitations, and Future Research}

Although we are convinced that our study has several strengths, and that the results provide crucial insights into the importance of employee relations and conditions for distributed leadership research, we are aware of limitations that must be addressed in light of interpreting the findings. A first strength of the present study is the half-longitudinal design, which enabled us to draw first path-related conclusions on the proposed relationships. Perceived autonomy is a time-preceding condition that can enhance employees' active participation in leadership tasks. Additionally, if employees' take over leadership responsibilities and engage in practicing leadership tasks they also perceive more occupational self-efficacy. Nonetheless, the small sample size $(N=67)$ substantially reduced the statistical power of the study. Failing to confirm the hypothesized mediation effect can be attributed to low statistical power, though it does not threaten the validity of the found significant effects. 
Another limitation concerns the two-wave design, as a three-wave design is preferred for testing real mediation effects (Taris and Kompier 2006). In the present study we analyzed the mediator- as well as the outcome-variable at the same time points, therefore it was not possible to investigate the time-related effect between DLA and occupational self-efficacy in the mediation analyses. Future studies could include a third measurement point to investigate the time-related mediation-effect of DLA at T2 on occupational self-efficacy at T3. A further limitation of twowave-studies is that the form of change cannot be assessed, it is only an increment of difference between two time points which is linear (Ployhart and Vandenberg 2010). In the present study, between the two time points employees began their active leadership participation by discussing and making joint decisions about the participation in the distributed leadership project. While these activities may have been the main factor in the changes from T1 to T2, many other factors may have been involved, including measurement error (Ployhart and Vandenberg 2010). Although structural equation modelling would have better accounted for measurement error, the small sample size prevented the use of models with latent variables. With respect to testing the proposed relationships as a morphogenetic cycle (Archer 1982), at least four measurements points would have been required. Owing to the restrictions of the current study, our findings can only be interpreted as first hints for the proposed mediation and the morphogenetic cycle and future research could investigate if heightened occupational self-efficacy can alter structural properties such as perceived autonomy over time.

Investigating one municipality that implements distributed leadership practices is a further limitation of this study, as generalizability of the findings to other populations may be substantially restricted. Additionally, the high percentage of female participants and the high educational level of the employees also reduces the generalizability of the findings. Further research could investigate DLA in different economic branches, with a broad range of firms, and which includes a heterogeneous sample with respect to gender and education. The Danish culture is also worth mentioning, as there is a tradition of employee participation and low power distance. As Danes, the employees in this sample may therefore already be accustomed to a relatively high degree of leadership participation and autonomy at work, and therefore more favorable to distributed leadership than could be expected globally. Attitudes to DLA and therefore the effects, could be expected to be different in high power distance cultures in which autonomy and DLA probably may be less important for the development of occupational selfefficacy. Future studies could address these cultural differences.

Surveying only one predictor and one criterion variable of DLA is another limitation of the present study. Future research on DLA with democratic potential could include several possible predictors (e.g. democratic organizational structures, organizational climate, formal participative/ democratic leadership forms) and outcomes (e.g. job satisfaction, organizational commitment, and especially health indicators and community-related behaviors that foster societal welfare) to provide a more comprehensive nomological network. Such research will deliver important knowledge and insights on the development, in addition to the effects of DLA.

A final limitation we want to mention is that all three core variables were self-rated at both time points, which may have induced a common method bias. Still, we were interested in employees' individually perceived autonomy, their active participation in leadership tasks and their occupational self-efficacy. We assume that self-ratings deliver a closer picture of employees' reality than might supervisor ratings for these constructs. Moreover, perceived autonomy was analyzed at T1 and DLA as well as occupational self-efficacy at T2, this may have reduced common method bias effects to some extent, CFAs and AVE analyses provide evidence of the distinctness of the constructs. 
Acknowledgements Open access funding provided by University of Innsbruck and Medical University of Innsbruck.

Open Access This article is distributed under the terms of the Creative Commons Attribution 4.0 International License (http://creativecommons.org/licenses/by/4.0/), which permits unrestricted use, distribution, and reproduction in any medium, provided you give appropriate credit to the original author(s) and the source, provide a link to the Creative Commons license, and indicate if changes were made.

\section{References}

Archer, Margaret S. 1982. Morphogenesis versus structuration: On combining structure and action. British Journal of Sociology 33: 455-483.

Axtell, Carolyn M., and Sharon K. Parker. 2003. Promoting role breadth self-efficacy through involvement, work redesign and training. Human Relations 56: 113-131.

Bandura, Albert. 1977. Self-efficacy: Toward a unifying theory of behavioral change. Psychological Review 84: 191-215.

Bandura, Albert. 1997. Self-efficacy. The exercise of control. New York: W. H. Freeman and Company.

Bolden, Richard. 2011. Distributed leadership in organizations: A review of theory and research. International Journal of Management Reviews 13: 251-269.

Bolden, Richard, Gregory Petrov, and Jonathan Gosling. 2008. Tensions in higher education leadership: Towards a multi-level model of leadership practice. Higher Education Quarterly 62: 358-376.

Brislin, Richard W. 1986. The wording and translation of research instruments. In Field methods in cross-cultural research, Vol. 8, Cross-cultural research and methodology series, ed. Walter J. Lonner and John W. Berry, 137-164. Beverly Hills: Sage.

Carson, Jay B., Paul E. Tesluk, and Jennifer A. Marrone. 2007. Shared leadership in teams: An investigation of antecedent conditions and performance. Academy of Management Journal 50: 1217-1234.

Cole, David A., and Scott E. Maxwell. 2003. Testing mediational models with longitudinal data: Questions and tips in the use of structural equation modeling. Journal of Abnormal Psychology 112: 558-577.

Conger, Jay A., and Rabindra N. Kanungo. 1988. The empowerment process: Integrating theory and practice. Academy of Management Review 13: 471-482.

D’Innocenzo, Lauren, John E. Mathieu, and Michael R. Kukenberger. 2014. A meta-analysis of different forms of shared leadership - Team performance relations. Journal of Management, first published on March 10, 2014 as doi:10.1177/0149206314525205.

Daspit, Josh, C. Justice Tillman, Nancy G. Boyd, and Victoria Mckee. 2013. Cross-functional team effectiveness: An examination of internal team environment, shared leadership, and cohesion influences. Team Performance Management 19: 34-56.

Denis, Jean-Louis, Ann Langley, and Viviane Sergi. 2012. Leadership in the plural. The Academy of Management Annals 6: 211-283.

Dierksmeier, Claus. 2016. What is humanistic about humanistic management? Humanistic Management Journal 1: $9-32$.

Fitzgerald, Louise, Ewan Ferlie, Gerry McGivern, and David Buchanan. 2013. Distributed leadership patterns and service improvement: Evidence and argument from English healthcare. The Leadership Quarterly 24: 227-239.

Fornell, Claes, and David F. Larcker. 1981. Evaluating structural equation models with unobservable variables and measurement error. Journal of Marketing Research 18: 39-50.

Gecas, Victor. 1989. The social psychology of self-efficacy. Annual Review of Sociology 15: 291-316 Retrieved from http://www.jstor.org/stable/2083228.

Gefen, David, and Detmar W. Straub. 2005. A practical guide to factorial validity using PLS-graph: Tutorial and annotated example. Communications of the Association for Information Systems 16: 91-109.

George, Vicki, Laura J. Burke, Beth Rodgers, Nancy Duthie, Mary Lou Hoffmann, Vicki Koceja, Alice Kramer, Joan Maro, Pam Minzlaff, Sandi Pelczynski, Mary Schmidt, Bev Westen, Jomarie Zielke, Genee Brukwitzki, and Linda L. Gehring. 2002. Developing staff nurse shared leadership behavior in professional nursing practice. Nursing Administration Quarterly 26: 44-59.

Graham, John W., Patricio E. Cumsille, and Elvira Elek-Fisk. 2003. Methods for Handling Missing Data. Handbook of Psychology 4: 87-114.

Gronn, Peter. 2000. Distributed properties. A new architecture for leadership. Educational Management \& Administration 28: 317-338.

Gronn, Peter. 2002. Distributed leadership as a unit of analysis. The Leadership Quarterly 13: 423-451.

Gronn, Peter. 2008. The future of distributed leadership. Journal of Educational Administration 46: 141-158. 
Gronn, Peter. 2009. Leadership configurations. Leadership 5: 381-394.

Hackman, J. Richard, and Greg R. Oldham. 1975. Development of the job diagnostic survey. Journal of Applied Psychology 60: 159-170.

Hackman, J. Richard, and Greg R. Oldham. 1980. Work redesign. Reading: Addison-Wesley.

Hannah, Sean T., John J. Sumanth, Paul Lester, and Fabrice Cavarretta. 2014. Debunking the false dichotomy of leadership idealism and pragmatism: Critical evaluation and support of newer genre leadership theories. Journal of Organizational Behavior 35: 598-621.

Harris, Alma. 2013. Distributed leadership: Friend or foe? Educational Management Administration \& Leadership 41: 545.

Hayes, Andrew F. 2013. Introduction to mediation, moderation, and conditional process analysis. A regressionbased approach. New York: The Guilford Press.

Heller, Frank. 2003. Participation and power: A critical assessment. Applied Psychology: An International Review 52: 144-163.

Hoch, Julia E. 2013. Shared leadership and innovation: The role of vertical leadership and employee integrity. Journal of Business and Psychology 28: 159-174.

$\mathrm{Hu}, \mathrm{Li}-\mathrm{Tze}$, and Peter M. Bentler. 1998. Fit indices in covariance structure modeling: Sensitivity to underparameterized model misspecification. Psychological Methods 3: 424-453.

Hulpia, Hester, Geert Devos, Yves Rosseel, and Peter Vlerick. 2012. Dimensions of distributed leadership and the impact on teacher's organizational commitment: A study in secondary education. Journal of Applied Social Psychology 42: 1745-1784.

Ishikawa, Jun. 2012. Transformational leadership and gatekeeping leadership: The roles of norm for maintaining consensus and shared leadership in team performance. Asia Pacific Journal of Management 29: 265-283.

Jønsson, Thomas, Christine Unterrainer, Hans-Jeppe Jeppesen, and Ajay K. Jain. 2016. Measuring distributed leadership agency in a hospital context: Development and validation of a new scale. Journal of Health Organization and Management 30: 908-926.

Katz, Daniel, and Robert L. Kahn. 1978. The social psychology of organizations. New York: Wiley.

Kline, Rex B. 1998. Principles and practices of structural equation modeling. New York: Guilford.

Kohn, Melvin L., and Carmi Schooler. 1973. Occupational experience and psychological functioning: An assessment of reciprocal effects. American Sociological Review 38: 97-118 Retrieved from http://www.jstor.org/stable/2094334.

LeBreton, James M., and Jenell L. Senter. 2008. Answers to 20 questions about interrater reliability and interrater agreement. Organizational Research Methods 11: 815-852.

Leithwood, Kenneth, Blair Mascall, Tiiu Strauss, Robin Sacks, Nadeem Memon, and Anna Yashkina. 2007. Distributing leadership to make schools smarter: Taking the ego out of the system. Leadership and Policy in Schools 6: 37-67.

Pereira Lopes, Miguel, Miguel Pina e Cunha, Stephan Kaiser, and Gordon Müller-Seitz. 2009. Positive organizational scholarship: Embodying a humanistic perspective on business. In Humanism in business, ed. Heiko Spitzeck, Michael Pirson, Wolfgang Amann, Shiban Khan, and Ernst von Kimakowitz, 278-298. Cambridge: Cambridge University Press.

Maak, Thomas, and Nicola Pless. 2009. The leader as responsible change agent: Promoting humanism in and beyond business. In Humanism in Business, ed. Heiko Spitzeck, Michael Pirson, Wolfgang Amann, Shiban Khan, and Ernst von Kimakowitz, 358-374. Cambridge: Cambridge University Press.

Mascall, Blair, Kenneth Leithwood, Tiiu Straus, and Robin Sacks. 2008. The relationship between distributed leadership and teachers' academic optimism. Journal of Educational Administration 46: 214-228.

Mayrowetz, David. 2008. Making sense of distributed leadership: Exploring the multiple usages of the concept in the field. Educational Administration Quarterly 44: 424-435.

McCall, John J. 2001. Employee voice in corporate governance: A defense of strong participation rights. Business Ethics Quarterly 11: 195-213.

Mehra, Ajay, Brett R. Smith, Andrea L. Dixon, and Bruce Robertson. 2006. Distributed leadership in teams: The network of leadership perceptions and team performance. The Leadership Quarterly 17: 232-245.

Melé, Domènec. 2009. Current trends in humanism and business. In Humanism in Business, ed. Heiko Spitzeck, Michael Pirson, Wolfgang Amann, Shiban Khan, and Ernst von Kimakowitz, 123-140. Cambridge: Cambridge University Press.

Mortimer, Jeylan T., and Jon Lorence. 1979. Occupational experience and the self-concept: A longitudinal study. Social Psychology Quarterly 42: 307-323 Retrieved from http://www.jstor.org/stable/3033802.

Murphy, Joseph, Mark Smylie, David Mayrowetz, and Karen S. Louis. 2009. The role of the principal in fostering the development of distributed leadership. School Leadership and Management 29: 181-214.

Parker, Sharon K. 1998. Enhancing role breadth self-efficacy: The roles of job enrichment and other organizational interventions. Journal of Applied Psychology 83: 835-852.

Pateman, Carole. 1970. Participation and democratic theory. Cambridge: Cambridge University Press. 
Pearce, Craig L., and Jay A. Conger. 2003. All those years ago: The historical underpinnings of shared leadership. In Shared leadership: Reframing the hows and whys of leadership, ed. Craig L. Pearce and Jay A. Conger, 1-18. Thousand Oaks: Sage.

Pearce, Craig L., Christina L. Wassenaar, and Charles C. Manz. 2014. Is shared leadership the key to responsible leadership? The Academy of Management Perspectives 28: 275-288.

Peus, Claudia, and Dieter Frey. 2009. In In Humanism in business, ed. Heiko Spitzeck, Michael Pirson, Wolfgang Amann, Shiban Khan, and Ernst von Kimakowitz, 260-277. Cambridge: Cambridge University Press.

Pirson, Michael. 2009. Social entrepreneurship: A blueprint for humane organizations? In Humanism in business, ed. Heiko Spitzeck, Michael Pirson, Wolfgang Amann, Shiban Khan, and Ernst von Kimakowitz, 248-259. Cambridge, UK: Cambridge University Press.

Pirson, Michael, and Paul R. Lawrence. 2010. Humanism in business - Towards a paradigm shift? Journal of Business Ethics 93: 553-565.

Pirson, Michael, Kenneth Goodpaster, and Claus Dierksmeier. 2016. Human dignity and business. Business Ethics Quarterly 26: 465-478.

Ployhart, Robert E., and Robert J. Vandenberg. 2010. Longitudinal research: The theory, design, and analysis of change. Journal of Management 36: 94-120.

Satorra, A. and Bentler, P.M. 1999. A scaled difference chi-square test statistic for moment structure analysis. Unpublished technical report, Barcelona: University Pompeu Fabra.

Scholz, Urte, Benicio G. Doña, Shonali Sud, and Ralf Schwarzer. 2002. Is general self-efficacy a universal construct? Psychometric findings from 25 countries. European Journal of Psychological Assessment 18: $242-251$.

Schyns, Birgit, and Gernot von Collani. 2002. A new occupational self-efficacy scale and its relation to personality constructs and organizational variables. European Journal of Work and Organizational Psychology 11: 219-241.

Seibert, Scott E., Gang Wang, and Stephen H. Courtright. 2011. Antecedents and consequences of psychological and team empowerment in organizations: A meta-analytic review. Journal of Applied Psychology 96: 981-1003.

Sitzmann, Traci, and Gillian Yeo. 2013. A meta-analytic investigation of the within-person self-efficacy domain: Is self-efficacy a product of past performance or a driver of future performance? Personnel Psychology 66: 531-568.

Small, Erika E., and Joan R. Rentsch. 2010. Shared leadership in teams: A matter of distribution. Journal of Personnel Psychology 9: 203-211.

Spillane, James. 2006. Distributed leadership. San Francisco: Jossey-Bass.

Spillane, James, and John B. Diamond. 2007. Distributed leadership in practice. New York: Teachers College Press.

Spillane, James, Richard Halverson, and John B. Diamond. 2004. Towards a theory of school leadership practice: Implications of a distributed perspective. Journal of Curriculum Studies 36: 3-34.

Spitzeck, Heiko, Michael Pirson, Wolfgang Amann, Shiban Khan, and Ernst von Kimakowitz, eds. 2009. Humanism in Business. Cambridge: Cambridge University Press.

Spitzeck, Heiko, Michael Pirson, Ernst von Kimakowitz, and Claus Dierksmeier. 2010. The humanistic management network. Journal of Psychology 218: 246-248.

Spreitzer, Gretchen. 1995. Psychological empowerment in the workplace: Dimensions, measurement, and validation. Academy of Management Journal 38: 1442-1465.

Strauss, George. 2006. Worker participation - some under-considered issues. Industrial Relations 45: 778-803.

Taris, Toon W., and Michiel A.J. Kompier. 2006. Games researchers play - extreme-groups analysis and mediation analysis in longitudinal occupational health research. Scandinavian Journal of Work, Environment \& Health 32: 463-472.

Tian, Meng, Mika Risku, and Kaija Collin. 2016. A meta-analysis of distributed leadership from 2002 to 2013 : Theory development, empirical evidence and future research focus. Educational Management Administration \& Leadership 44: 146-164.

Turgut, Sarah, Alexandra Michel und Karlheinz Sonntag. 2014. Einflussfaktoren emotionaler Erschöpfung und Arbeitszufriedenheit. Anwendung eines integrativen Untersuchungsansatzes (determinants of emotional exhaustion and job satisfaction - Application of an integrative research approach). Zeitschrift für Arbeitsund Organisationspsychologie 58: 140-154.

Unterrainer, Christine, Michal Palgi, Wolfgang G. Weber, Anna Iwanowa, and Rainer Oesterreich. 2011. Structurally anchored organizational democracy: Does it reach the employee? Journal of Personnel Psychology 10: 118-132.

Wang, Danni, David A. Waldman, and Zhen Zhang. 2014. A meta-analysis of shared leadership and team effectiveness. Journal of Applied Psychology 99: 181-198. 
Weber, Wolfgang G., and Christine Unterrainer. 2012. The analysis of preconditions for the fostering of democratic behavioural orientations in business organizations -the ODEM questionnaire (POPD). In Democratic competences and social practices in organizations, ed. Wolfgang G. Weber, Michael Thoma, Annette Ostendorf, and Lynne Chisholm, 118-143. Wiesbaden: Springer VS.

Weber, Wolfgang G., Christine Unterrainer, and Birgit E. Schmid. 2009. The influence of organizational democracy on employees' socio-moral climate and prosocial behavioral orientations. Journal of Organizational Behavior 30: 1127-1149.

Wegge, Jürgen, Hans-Jeppe Jeppesen, Wolfgang G. Weber, Craig L. Pearce, Silvia A. Silvá, Alexander Pundt, Thomas Jønsson, Sandra Wolf, Christina L. Wassenaar, Christine Unterrainer, and Annika Piecha. 2010. Promoting work motivation in organizations: Should employee involvement in organizational leadership become a new tool in the organizational psychologists' kit? Journal of Personnel Psychology 9: 154-171.

Woods, Philip A. 2016. Authority, power and distributed leadership. Management in Education 30: 155-160.

Woods, Philip A., and Peter Gronn. 2009. Nurturing democracy. The contribution of distributed leadership to a democratic organizational landscape. Educational Management Administration \& Leadership 37: 430-451.

Woods, Philip A. and Glenys J. Woods. 2013. Deepening distributed leadership: A democratic perspective on power, purpose and the concept of the self. Vodenje v vzgoji in izobraževanju (Leadership in Education) 2: 17-40. English version online. Available at https://herts.academia.edu/PhilipWoods. Accessed 12 Jan 2017.

Woods, Philip A., Nigel Bennett, Janet A. Harvey, and Christine Wise. 2004. Variabilities and dualities in distributed leadership. Findings from a systematic literature review. Educational Management Administration Leadership 32: 439-457.

Yammarino, Francis J., Eduardo Salas, Andra Serban, Kristie Shirreffs, and Marissa L. Shuffler. 2012. Collectivistic leadership approaches: Putting the "we" in leadership science and practice. Industrial and Organizational Psychology 5: 382-402.

Yukl, Gary, Angela Gordon, and Tom Taber. 2002. A hierarchical taxonomy of leadership behavior: Integrating a half century of behavior research. Journal of Leadership \& Organizational Studies 9: 15-32. 